Address for Correspondence: Michael D. Brennan, MD, FRCPI, FACE, FRCSI (Hon.), Professor of Medicine, Consultant in Endocrinology, Medical Director Mayo Clinic Program in Professionalism and Values, Mayo Clinic College of Medicine, Rochester, MN 55905, USA.

Email: brennan.michael@mayo.edu

\begin{tabular}{|c|}
\hline Access this article 0 \\
\hline $\begin{array}{l}\text { Website: } \\
\text { www.intern-med.com }\end{array}$ \\
\hline $\begin{array}{l}\text { DOI: } \\
\text { 10.1515/jtim-2016-0017 }\end{array}$ \\
\hline Quick Response Code: \\
\hline 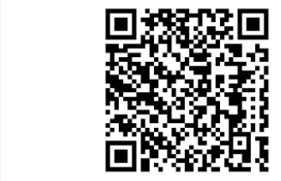 \\
\hline
\end{tabular}

\title{
The role of professionalism in clinical practice, medical education, biomedical research and health care administration
}

\author{
Michael D. Brennan \\ Mayo Clinic College of Medicine, Rochester, MN 55905, USA
}

Medical doctors are granted a license to practice following years of study and diligent assessment. Licensure is granted on the understanding that doctors will use their knowledge and skills to meet and advance the needs of their patients and, in so doing, place those needs ahead of other considerations, most notably self-interest. The compact thus formed engenders trust between the medical profession, patients, and society. The smooth functioning of a modern healthcare system cannot occur in the absence of trust. The adverse experience of healthcare systems in which doctors are no longer trusted serves as a sharp reminder of this. Well publicized examples point to poor medical outcomes, patient dissatisfaction, and resentment, which can spiral out of control and wasteful medical care delivery. Doctors have a solemn duty and responsibility therefore to behave in a manner that promotes patient and societal trust. This applies not only in clinical practice, but also in the integrity of medical research and how medical students and residents are optimally prepared for medical careers.

Essential levels of trust can be achieved and sustained through the embrace and consistent expression of professionalism attitudes and behaviors. These include integrity, accountability, motivation, altruism, empathy, and the pursuit of excellence through lifelong learning. A number of formal definitions of professionalism have been proposed all of which include the word trust. At Mayo Clinic, we define it as "engendering trust by doing the right things, for the right reasons, in the right way, and at the right time." We believe this definition incorporates all the key attitudes and behaviors. Allied elements include well developed interpersonal and communication skills. These are required in order to overcome the discrepancy in knowledge and expertise between highly trained doctors and the lay public. Such discrepancies add to the sense of patient vulnerability that is a constant companion of sickness and ill health.

The past 20 years has seen an international resurgence of interest in the importance of professionalism training and assessment. In the United States, educational regulatory bodies, including the American Association of Medical Colleges and the American College of Graduate Medical Education, have elevated professionalism as one of six core competencies that must be taught, inculcated, and assessed during undergraduate and graduate medical education. Satisfactory performance is required for graduation and board certification. Another important landmark is the Charter on Professionalism developed and published jointly by the American Board of Internal Medicine Foundation, the American College of Physicians and their European counterparts. Since publication, over 130 medical societies and organizations around the world have signed the Charter. Scholarly articles on professionalism education and assessment continue to appear in prestigious peerreviewed medical journals. They serve to support and guide students, medical educators, faculty members, administrators, clinicians, as well as basic and clinical translational medical researchers.

Professional formation of students and graduates in training can best be achieved by establishing educational milestones against which the learners can be assessed. 
Competency milestones have been established and published and serve as a guide for educators. These may be modified and adjusted to better align with unique features of national educational models. The establishment of such milestones and their rigorous assessment sends a strong signal to both faculty and learners concerning the importance that is being placed by institutional and organizational leadership. Accumulated experience on the benefits of other healthcare initiatives in quality and patient safety have borne this out.

Positive formative professionalism education requires that medical institutions establish and maintain conducive administrative practice, and educational and research supportive environments. Such environments are those in which learners are exposed to teachers and supervisors who are positive role models. Nothing is more destructive of learners' professionalism aspirations than being exposed to, and adversely influenced by, teachers and faculty members who fall short of modeling the attitudes and behaviors of professionalism. It is the duty of leaders to identify and engage with such individuals and, when possible, institute remedial action and assess the impact. If remedial action fails then it is the duty of leadership to protect learners from the toxic influence of those individuals regardless of their institutional power and standing. Administrative decisions and policies adopted by institutional leadership are closely watched by staff at all levels within an organization. Staff morale and professionalism aspirations are seriously undermined if and when policies are considered inconsistent with the stated mission and purpose of the organization. This is what is commonly referred to as "walking the talk" or, in other words, there is close alignment between what is said and what is done. The highest professionalism standards cannot be sustained if work schedules are over burdensome and the work of doctors is not adequately appreciated and rewarded. Organizational failure in this regard leads to cynicism, poor morale, physician burnout, flawed teamwork and coordination, and ultimately poor medical care and outcomes.

Contrast with this the benefits that accrue to patients, staff and the medical organizations from the combination of individual and organizational professionalism. These have been well documented through empiric studies in the medical and social psychology journals, leadership and human resources manuals, as well as modern quality and safety literature. Staff morale and commitment improve reflecting enhanced sense of meaning and purpose of work, reduced staff turnover, greater interdisciplinary coordination and teamwork that, in turn, result in improved quality, patient safety and value. The result is an increase in organizational prestige and reputation that attracts patients and also outstanding clinicians, researchers, and educators who aspire to conduct their careers in such supportive and rewarding environments.
Several approaches to organizational professionalism and formative education hold great promise and are being adopted by academic medical centers in the United States. At the Mayo Clinic, a patient focused, high quality integrated academic medical center has established a formal Program in Professionalism and Values with responsibility for professionalism education, training, and research. The goal was to build upon a rich, century old, mission-driven patient-centered culture. In the words of one of the founding brothers, Dr. William Mayo, spoken in 1910, "the needs of the patient come first and in order that the sick gain benefit from new knowledge, a Union of Forces (i.e. teamwork) is needed." On parsing this sentence, one finds all the attributes and behaviors of professionalism. As such, it is organizational principle that has elevated Mayo Clinic as being consistently ranked as the most trusted name in American healthcare.

Others can learn and benefit from the Mayo experience. The rewards are multifaceted and enduring. Most importantly, they engender and justify patient and societal trust in the medical profession without which meaningful advances in cost-effective clinical care, quality, and safety delivery will not occur. Needed advances in biomedical research will be retarded and frustrated, particularly those related translational clinical research, which, to be successful, requires that patients' trust be established as a pre-condition for enrollment in clinical trials.

\section{ADDITIONAL READING}

To read additional information related, here I recommend several literatures published by Annals of Internal Medicine $(2002)^{[1]}$, New England Journal of Medicine (2015) ${ }^{[2]}$, BMJ Open (2015) ${ }^{[3]}$ and Mayo Clinic Proceedings (2014) ${ }^{[4]}$, which are listed as references.

\section{Conflict of Interest}

None declared.

\section{REFERENCES}

1. ABIM Foundation; ACP-ASIM Foundation; European Federation of Internal Medicine. Medical Professionalism in the new millennium; a physician charter. Ann Intern Med 2002; 136: 243-6.

2. Blumenthal D, Hsiao W. Lessons from the East-China's Rapidly Evolving Healthcare System. New Eng J Med 2015; 372: 1281-5.

3. Tucker JD, Cheng Y, Wong B, Gong N, Nie JB, Zhu W, et al. Patient - physician mistrust and violence against physicians in Guangdong Province, China: a qualitative study. BMJ Open 2015; 5:e008221.

4. Brennan MD, Monson V. Professionalism: Good for Patients and HealthCare Organizations. Mayo Clin Proc 2014; 89: 644-52.

How to cite this article: Brennan MD. The role of professionalism in clinical practice, medical education, biomedical research and health care administration. J TransI Intern Med 2016; 4:64-5. 